\section{Tropical landforms}

Tropical Geomorphology: A Study of Weathering and Landform Development in Warm Climates. (Focal Problems in Geography Series.) By Michael F. Thomas. Pp. xii +332 . (Macmillan : London and Basingstoke; distributed in USA and Canada by Halsted Press.) $£ 2.95$.

THE terms bornhardt and inselberg reflect the keen interest taken by German scientists in tropical landforms during the late 19th century. The British came in strongly in 1911 with J. D. Falconer's account of the geology of northern Nigeria. Comprehensive summaries appeared later, the chief being S. Passarge's Panoramen afrikanischer: Inselberg-landschaften (1928) and Karl Sapper's remarkable Geomorphologie der feuchten Tropen (1935), and recently the French have produced much literature on tropical landscapes, including Jean Tricart's Le modelé des régions chaudes, forêts ét savanes (1965) which was translated into English by C. J. K. de Jonge in 1972.

Now Dr Thomas, having published numerous percipient articles, has produced the first full treatment of tropical geomorphology written originally in English. He balances the results of his own wide-ranging field studies against the findings of other warmclimate geomorphologists, and summarises carefully the issues that are fundamental to an understanding of the development of tropical landforms and regoliths. In addition, by analysing in detail weathering processes and their relationships to common morphometry, he ensures that the reader understands geomorphogenesis anywhere under warm bioclimatic conditions in which the work of wind, frost and waves is absent.

Part 1 contains five chapters on weathering and in these the author stresses the increased tropical rate of endothermic chemical reactions, the stability of vast horizontal surfaces, and the frequent occurrence of silicate minerals in rock exposures. The description of the processes are set out clearly and concisely, particularly the eluviation of silica and the formation of duricrusts and of deep-seated profiles.

Part 2 discusses the character and development of the tropical terrain and includes chapters on distinctive individual landforms, on hill-slopes, and on pediments and pediplanation. The text ends with a bibliography and three indexes.

Throughout, the author recognises that the processes undergo complex variations in intensity and that inherited or relict forms may be part of the general picture. The landforms characteristic of the tropics are shown to experience a continuity of subaerial morphogenesis over a prolonged period during which interruptions by tectonic and climatic pulses are localised in space and time. Dr Thomas makes the reader aware of the many problems ahead and of the great progress made during the last few decades. His concise analysis combines clarity of exposition with clear-cut diagrams and ample quantification so successfully that it deserves to become straightaway the standard text on the geomorphology of the humid tropics.

Robert P. Beckinsale

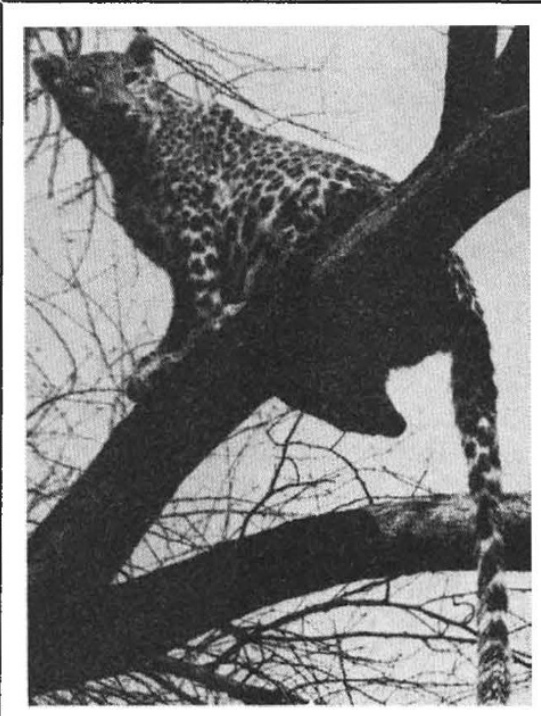

Thereby hangs a tail: a highly placed leopard watches for prey. From Tigerland. By Kailash Sankhal. (Collins London, May 1975.) £3.50.

\section{Antibiotic agents}

Mechanism of Action of Antimicrobial and Antitumor Agents (Antibiotics, vol. 3.) Edited by J. W. Corcoran and F E. Hahn. Pp. xii +742 . (Springer : Berlin and New York, 1975.) DM.188; $\$ 77.10$.

THIS volume is the third of a series and provides up to date information on many of the classes of antibiotics described in the first volume published eight years ago. In spite of the inclusion of 46 chapters, it is not a complete review and classes of antibiotic such as the actinomycins and nitrofurans, which are missing, will form the basis for a future volume. Among the 3,500 or so references are to be found a sprinkling of 1973 quotations, so the book is reasonably up to date, which is a good achievement for a publication of this complexity.

The book deals with antibiotics defined in the broadest sense of the word and chapters are included on alkaloids and synthetic chemicals which are clearly like antibiotics in their mechanism of action. Descriptions are given of a great variety of agents which have properties ranging from antibacterial and antiparasitic, to antitubercular and antitumour, and agents which are primarily useful as laboratory probes for investigating biological processes are also discussed. Indeed, some chapters contain accounts of chemicals which seem to have no practical value and which, presumably, are still looking for some disease to cure.

A clear sign of the emerging interest in antibiotics as antitumour agents is evident from the first section of the book on agents that interfere with nucleic acid biosynthesis. The majority of the compounds described in this section have some antitumour properties, and though only bleomycin and members of the anthracycline group are of proven clinical value, it is apparent that this is an area in which new discoveries may well be made. A second section deals with agents that interfere with protein biosynthesis and a miscellaneous final section is devoted to agents that interfere with specific enzymes and with membrane or cell wall biosynthesis and with agents whose mechanism of action is unknown.

The editors have obviously given a lot of thought to the design of the book and to the selection of authors. What emerges is a pleasingly uniform series of chapters dealing with the mechanism of action of various antibiotics. With few exceptions, the chapters are authoratitive and provide critical accounts rather than just a catalogue of reported work.

Mechanisms of selectivity are discussed in a few of the chapters. Ethidium, for example, is an antiparasitic agent probably because it interacts specifically with closed circular molecules of extrachromosomal DNA. The characteristic sensitivity of squamous cell carcinoma to bleomycin is explained by the fact that this tumour type concentrates the drug and is also unable to convert it to its non-toxic form. Unfortunately, many authors, having described the probable mechanism of action of a compound, make no effort to explain the basis of its selectivity. Why, for instance, should one intercalating agent be an antimalarial, another antitumour, and yet another just a poison? Perhaps the reasons for selectivity are still little understood, but a few comments by each author, even if only of a speculative nature, would have rounded off a good book.

All in all this is a fine volume which, combined with the promised volume dealing with agents not covered in this book, provides a comprehensive and critical survey of our present day knowledge of antibiotics and related compounds.

T. A. Connors 